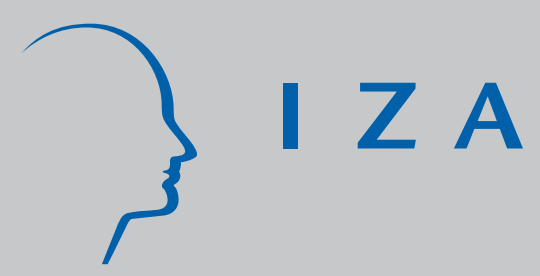

IZA DP No. 82

Privacy, time consistent optimal labor income taxation and education policy

Kai A. Konrad

December 1999 


\title{
Privacy, time consistent optimal labor income taxation and education policy
}

\author{
Kai A. Konrad \\ Free University of Berlin, University of Bergen, \\ CEPR and IZA \\ Discussion Paper No. 82 \\ December 1999
}

\author{
IZA \\ P.O. Box 7240 \\ D-53072 Bonn \\ Germany \\ Tel.: +49-228-3894-0 \\ Fax: +49-228-3894-210 \\ Email: iza@iza.org
}

This Discussion Paper is issued within the framework of IZA's research area The Welfare State and Labor Markets. Any opinions expressed here are those of the author(s) and not those of the institute. Research disseminated by IZA may include views on policy, but the institute itself takes no institutional policy positions.

The Institute for the Study of Labor (IZA) in Bonn is a local and virtual international research center and a place of communication between science, politics and business. IZA is an independent, nonprofit limited liability company (Gesellschaft mit beschränkter Haftung) supported by the Deutsche Post AG. The center is associated with the University of Bonn and offers a stimulating research environment through its research networks, research support, and visitors and doctoral programs. IZA engages in (i) original and internationally competitive research in all fields of labor economics, (ii) development of policy concepts, and (iii) dissemination of research results and concepts to the interested public. The current research program deals with (1) mobility and flexibility of labor markets, (2) internationalization of labor markets and European integration, (3) the welfare state and labor markets, (4) labor markets in transition, (5) the future of work, (6) project evaluation and (7) general labor economics.

IZA Discussion Papers often represent preliminary work and are circulated to encourage discussion. Citation of such a paper should account for its provisional character. 
IZA Discussion Paper No. 82

December 1999

\section{ABSTRACT}

\section{Privacy, time consistent optimal labor income taxation and education policy ${ }^{*}$}

Incomplete information is a commitment device for time consistency problems. In the context of time consistent labor income taxation privacy can lead to a Pareto superior outcome and increases the effectiveness of public education as a second best policy.

JEL Classification: H21, H23

Keywords: Privacy, commitment, time consistent income taxation

Kai A. Konrad

Free University of Berlin

Boltzmannstr. 20

14195 Berlin

Germany

Tel: +49308382005

Fax: +49308383330

Email: Kai.Konrad@wiwiss.fu-berlin.de

I thank Robin Boadway and Ray Rees for extremely valuable comments and suggestions. The usual caveat applies. 


\section{Introduction}

Technological constraints and monitoring costs, but also constitutions and laws in modern democracies, limit government's scope for information collection. It is sometimes argued that such provisions for guaranteeing privacy are necessary to protect individuals from a government that is, or may turn into, a Leviathan. This paper argues that limits to the government's access to information can be Pareto improving, making all individuals better off, even if the government is fully benevolent and strictly maximizes welfare in an economy with identical individuals if governmental policy suffers from time consistency problems.

The analysis of time consistent policy more generally, by Kydland and Prescott (1977), and time consistent taxation by Kydland and Prescott (1980) has stimulated considerable research on capital income taxation. Boadway, Marceau and Marchand (1996) draw attention to the fact that time consistency may be an even more important problem regarding optimal income tax policy and human capital investment. ${ }^{1}$ If the government chooses taxes when all private decisions are made, the government may find it optimal to tax and radically redistribute earnings. Full equalization of marginal utilities of income would be the time consistent optimal tax policy. ${ }^{2}$ Young individuals anticipate that time consistent optimal taxation will consist of a radical income redistribution policy regarding their future income. This dramatically reduces their incentives to invest in education and other forms of human capital that increase an individual's earnings' potential. ${ }^{3}$ Boadway et al. (1996) compare a tax policy that is optimal ex-ante (before individuals

\footnotetext{
${ }^{1}$ A less extreme time consistency problem in optimal income taxation has been considered by Dillén and Lundholm (1996). They consider optimal income taxation in a dynamic framework. If the government can re-optimize optimal tax policy in each period, using information about individual productivities revealed in previous periods, this yields a less severe, but technically even more involved time consistency problem known as the 'ratchet problem'.

${ }^{2}$ See, e.g., Atkinson (1973) for discussion. The uncertainty about future income and productivity creates an insurance demand and this is the standard justification for redistributive optimal income taxation. Varian (1980) and Sinn (1995) have made this argument very clear.

${ }^{3}$ Empirically, a strong link between educational investment and the individual returns of this investment is well established. For an overview on the U.S. see Mincer (1994). For Sweden see Edin and Topel (1997, pp. 173n.). Also, the empirically based general equilibrium model by Trostel (1993) suggests that income taxation strongly affects individual educational choice.
} 
decide about their human capital investment) and ex-post optimal income taxation (when actual incomes are given and observed). In their framework, the time consistent outcome is necessarily an equilibrium in which all ability types choose the same (typically zero) education investment and all have the same final income. Mandatory education could eliminate the underinvestment problem in their framework, provided that individuals can be forced to adopt education.

As in most time consistency problems the quintessential question is about commitment. The government may well be aware of the incentive problems. However, time consistent optimization of taxes and redistribution takes place when human capital investment already has occured and when these choices are given. A government may want to commit to a less radical redistributive policy, in order to stimulate more investment. Boadway and Keen (1998) show that the possibility of tax evasion and commitment on a lax enforcement policy can partially overcome the time consistency problem. Kehoe (1989) highlights tax competition as a possibly beneficial countervailing incentive if a benevolent government faces a time consistency problem in taxation. Kotlikoff, Persson and Svensson (1988) consider institutions that are costly to change. Persson and Tabellini (1994) suggest delegating the optimal tax decision to a person or group that has incentives different from those of the welfarist government. But can these mechanisms lead to credible commitment to tax rates that apply twenty or thirty years later?

This paper proposes a different commitment mechanism: incomplete information. The argument applies to other commitment problems as well, but is developed here in the context of optimal income taxation and human capital investment using a variant of the model by Boadway et al. (1996): individuals first choose their education investment and the government chooses its tax policy for given education effort. However, a further degree of freedom is added. Once the government has chosen its tax policy, individuals can still choose their actual work effort that determines individuals' actual earnings. The endogenous work effort choice offers an important insight. It shows that incomplete information is a commitment device that can overcome problems in time consistent taxation and can yield a Pareto improvement. For full information the results in Boadway et al. (zero equilibrium education) are reproduced. Incomplete information, however, leaves some information rent to high productivity individuals. This rent cannot be taxed away, and generates incentives for investment in education. Equilibrium education becomes strictly positive and the hold-up problem that is generated by time consistent 
optimal taxation is partially alleviated. ${ }^{4}$

Also, with endogenous work effort, public provision of education as a second-best tool works better with incomplete information. With complete information and endogenous work effort, individuals are not willing to adopt education, even if it is provided for free (or mandatory). With incomplete information, a case for subsidized or freely provided education as a second best policy can be made.

\section{The Model}

Consider a two-period model ${ }^{5}$ with a continuum $[0,1]$ of individuals who are all identical in period 1. All individuals live for two periods. In period 1 they make an investment in education. The size of the investment of individual $i$ is $e_{i}$.

In period 2 individuals choose the amounts of their gross earnings $m_{i}$. Depending on the amount chosen, generating these earnings brings a disutility of effort. This disutility is assumed to be a strictly positive and thrice differentiable function $\psi\left(m_{i}\right)$ with derivatives $\psi^{\prime}\left(m_{i}\right)>0, \psi^{\prime \prime}\left(m_{i}\right)>0$, and $\psi^{\prime \prime \prime}\left(m_{i}\right) \geq 0$. The marginal disutility is positive, increasing in earnings, and convex ${ }^{6}$. These assumptions are plausible and well discussed in agency theory. In period 2 each individual is of one of two possible productivity types. The two types are characterized by disutility functions $\psi_{H}(m)$ and $\psi_{L}(m)$. We assume that $\psi_{L}(m)>\psi_{H}(m)>0$ for all $m \geq 0$. Hence, the ' $H$ '-type is more productive than the ' $L$ '-type, productivity meaning that a more productive individual is able to generate the same amount of income with less disutility, for instance because fewer hours are needed to generate this income. For simplicity we parametrize the productivity difference as a

\footnotetext{
${ }^{4} \mathrm{~A}$ related argument has been used by Kjerstad and Vagstad (1996) in an auction context. They show that too few bidders may enter an auction if entry has fixed cost and if the auctioning mechanism leaves too little expected agency rents to the bidders.

${ }^{5}$ It is straightforward to extend this model and its equilibrium results to an overlapping generations model with an infinite horizon. However, with an infinite horizon, equilibria could be supported in which the time consistency problem could be overcome, similar to sustainability of pay-as-you-go systems (Salant, 1991). These folk-theorem arguments are less appealing in overlapping generations models, however, because players (government or median voter, and individuals) change identity in an overlapping generations model.

${ }^{6}$ Convexity of the marginal effort function is assumed in order to rule out the desirability of a randomizing mechanism which has been discussed, e.g., in Stiglitz (1982).
} 
horizontal shift of the marginal disutility curve; that is, $\psi_{L}^{\prime}(m)=\psi_{H}^{\prime}(m+\Delta)$ for all levels of income, and for some strictly positive given $\Delta .^{7}$

The productivity of each individual is determined (by nature) at the beginning of period 2. The individual's probability of becoming highly productive is $p\left(e_{i}\right)$. The individual's investment $e_{i}$ in period 1 increases the probability that the individual becomes more productive. If no educational investment is made, the individual will have low productivity with probability one in period 2. The probability $p\left(e_{i}\right)$ is assumed to be a monotonically increasing function in educational investment. More specifically, I assume that $p(0)=0, \lim _{e_{i} \rightarrow 0} p^{\prime}\left(e_{i}\right)=\infty, p^{\prime}\left(e_{i}\right)>0, p^{\prime \prime}\left(e_{i}\right)<0$, and $\lim _{e_{i} \rightarrow \infty} p\left(e_{i}\right)<1 .{ }^{8}$

The individuals learn about the effect of their education investment at the beginning of period 2 and make their earnings decisions after observing the productivity type. We denote gross earnings and net income of an individual with high-productivity by $m_{H}$ and $x_{H}$ and gross earnings and net income of individuals with low-productivity by $m_{L}$ and $x_{L}$, respectively.

The individual likes consumption in period 2 , denoted as $x_{i}$, dislikes disutility of generating earnings, and also dislikes educational investment. Individual $i$ 's payoff from choices $\left(e_{i}, m_{H}, m_{L}\right)$ is

$$
U_{i}=-e_{i}+p\left(e_{i}\right)\left[u\left(x_{H}\right)-\psi_{H}\left(m_{H}\right)\right]+\left(1-p\left(e_{i}\right)\right)\left[u\left(x_{L}\right)-\psi_{L}\left(m_{L}\right)\right] .
$$

This is an expected utility with $\psi$ the disutility of effort function, and $u$ the utility of income which is assumed to be increasing in income and strictly concave. The gross earnings $m_{i}$ and net income $x_{i}$ can differ by an income tax or subsidy that will be introduced later.

I refer to $\left(-e_{i}\right)$ in (1) as to i's first-period utility, and to the latter terms in (1) as to $i$ 's second-period expected utility. It is not specified exactly what constitutes educational investment. One possible interpretation is that this investment is in the form of mental effort or forgone leisure in period 1 , which explains why these resources may enter additively separably in the payoff function. ${ }^{9}$

\footnotetext{
${ }^{7}$ This parametrization is mainly for simplicity. The results in this paper hold more generally. A more general sufficient condition is that $\psi_{H}\left(m_{H}\right)>\psi_{L}\left(m_{L}\right)$ whenever $m_{H}$ and $m_{L}$ are chosen such that $\psi_{H}^{\prime}\left(m_{H}\right)=\psi_{L}^{\prime}\left(m_{L}\right)$.

${ }^{8}$ The two-type assumption is for simplicity only and has been made in the optimal tax literature, e.g., by Stern (1982), Stiglitz (1982) and, in a related context, by Boadway and Marchand (1995).

${ }^{9}$ The additive separability of payoff is made only for simplicity.
} 


\section{The laissez-faire outcome}

Before considering time consistent optimal income taxes we analyse the laissez-faire equilibrium outcome. If there is no government to impose restrictions on earnings choices and to implement redistributive taxation, each individual maximizes (1) subject to $x_{H}=m_{H}$ and $x_{L}=m_{L}$.

The first order conditions which implicitly determine the optimal values $\left(e^{*}, m_{H}^{*}, m_{L}^{*}\right)$ are

$$
\begin{aligned}
u^{\prime}\left(m_{H}^{*}\right) & =\psi_{H}^{\prime}\left(m_{H}^{*}\right) \\
u^{\prime}\left(m_{L}^{*}\right) & =\psi_{L}^{\prime}\left(m_{L}^{*}\right)
\end{aligned}
$$

and

$$
p^{\prime}\left(e^{*}\right)\left\{\left[u\left(m_{H}^{*}\right)-\psi_{H}\left(m_{H}^{*}\right)\right]-\left[u\left(m_{L}^{*}\right)-\psi_{L}\left(m_{L}^{*}\right)\right]\right\}=1 .
$$

These conditions have the natural interpretations that earnings effort is optimally chosen so that marginal utility of income and marginal disutility of generating income are equal for each type of productivity, and that the marginal benefit of investment in education equals the marginal investment cost. The marginal benefit from an increase in $e_{i}$ is the increase in probability to become the highly productive type times the difference between utilities of persons with high and low productivities.

Note that the high effectiveness of the first marginal units of education investment implies that $e^{*}>0$ in this equilibrium.

\section{Taxation and time consistency}

Consider now income taxation by a benevolent government. The solution of ex-ante optimal (time inconsistent) taxation is omitted here. The benevolent government would choose a tax schedule $T_{i}=T\left(m_{i}\right)$ to maximize the expected utility $U^{i}$ as in (1) with

$$
x_{i}=m_{i}-T_{i}
$$

subject to the government's budget constraint and subject to the individually rational choices of income and investment in education, $m_{i}$ and $e_{i}$. Accordingly, when choosing and announcing period 2's tax function at the beginning of period 1 , the government takes into account that redistributive taxation distorts the education decision. The solution is similar to the exante optimal tax problem with commitment considered in Boadway, Marceau 
and Marchand (1996) which they compare with a time consistent outcome. This paper analyses a different comparison: it considers only time consistent optimal tax policy and compares the cases with complete and incomplete information in the next two sections, showing that welfare with time consistent optimal taxation is higher if government is incompletely informed.

Summarizing, the time structure of games in these sections will be as follows. In STAGE 1 , individuals $i \in[0,1]$ choose their educational efforts $e_{i}$. In STAGE 2 , nature decides whether an individual is more or less productive, in the sense of having effort functions $\psi_{H}$ or $\psi_{L}$, with $p\left(e_{i}\right)$ individual $i$ 's probability for becoming highly productive. Individuals learn their own productivity at this stage. This concludes period 1. In STAGE 3 government implements the Mirrlees (1971) optimal tax policy for a given distribution of productivities. This tax policy is an income tax (or subsidy) as a function of observed gross income, and possibly, as a function of productivity, if the government can observe individual productivity. In STAGE 4 each individual chooses his or her actual gross income and pays taxes or receives subsidies accordingly.

\section{Complete information}

In this section we first solve the time consistent optimal tax problem at STAGE 3 for the case with complete information: the individuals and the government observe the individuals' productivities. Then we determine the individuals' incentives to invest in education in STAGE 1 for this case.

Suppose individuals have chosen their investment $e_{i}$ in period 1 , for each $i \in[0,1]$. If the government can observe individual productivities it can implement a standard income tax function that allows for controlling both each individual's earnings $m_{i}$ and their income net of taxes $x_{i}$ as in (5), subject to a budget constraint, by making the tax a function of productivity. The government maximizes individuals' period-2 expected utility

$$
W=\int_{0}^{1}\left[p\left(e_{i}\right)\left[u\left(x_{H}\right)-\psi_{H}\left(m_{H}\right)\right]+\left(1-p\left(e_{i}\right)\right)\left[u\left(x_{L}\right)-\psi_{L}\left(m_{L}\right)\right]\right] d i
$$

subject to a budget constraint

$$
\int_{0}^{1}\left[p\left(e_{i}\right) T_{H}+\left(1-p\left(e_{i}\right)\right) T_{L}\right] d i=0 .
$$


The constraint (7) requires that the total sum of tax revenue is zero and uses that all individuals with productivity $k \in\{L, M\}$ choose $m_{k}$ and pay taxes, $T_{k}$. Solving this problem yields first order conditions

$$
\psi_{H}^{\prime}\left(m_{H}\right)=u^{\prime}\left(m_{H}-T_{H}\right)=u^{\prime}\left(m_{L}-T_{L}\right)=\psi_{L}^{\prime}\left(m_{L}\right) .
$$

Together with (7), these conditions determine the optimal choices of earnings and redistributive taxes. In the optimum (8) all marginal utilities of consumption must be equal between all individuals. Otherwise a further redistribution could be designed that yields even higher welfare. Also, earnings are chosen efficiently: the marginal disutility of generating earnings equals the marginal utility of consuming net income.

If the government can observe each individual's productivity, it can implement this outcome simply by defining an appropriate tax function $T(m, k)$ with $k \in\{H, L\}$, for which the tax (or subsidy) depends on observed gross income and productivity. One straightforward way to implement this outcome is as follows. Suppose the optimal tax and subsidy for individuals with high and low productivities are $T_{H}^{* *}$ and $T_{L}^{* *}$, respectively. Then the government may choose income invariant but productivity dependent (poll) taxes $T(m, H) \equiv T_{H}^{* *}$ and $T(m, H) \equiv T_{H}^{* *}$. Given these taxes the individuals voluntarily choose the gross incomes that are efficient given their productivities.

Consider the utilities of individuals in the optimum. All have the same utility from consumption, since they have the same net income. However, the more productive individuals have a higher disutility of generating higher gross income. The difference in disutilities is

$$
\psi_{H}\left(m_{H}\right)-\psi_{L}\left(m_{L}\right)=\int_{0}^{m_{H}-m_{L}} \psi_{H}^{\prime}(m) d m>0 .
$$

An individual is strictly better-off from not being highly productive. ${ }^{10}$

Consider now STAGE 1: Individuals' incentive to invest in education in period 1. Since there is a continuum of individuals, each individual anticipates $T_{H}^{* *}$ and $T_{L}^{* *}$ for the two productivity types as independent of his or her own investment choice. Each individual will therefore choose $e_{i}^{*}=0$. Even though educational investment is extremely effective at the margin at $e_{i}^{*}=0$, an individual has no incentive to invest. Even the first unit of investment reduces the individual's expected utility. The investment is itself a cost

\footnotetext{
${ }^{10}$ This result is in line with Mirlees (1974) who has shown that the first best is likely to require utility to decrease with skill in the first best allocation.
} 
and lowers the individual's utility. In addition, it increases the individual's probability of becoming highly productive in period 2 , and, as has just been shown, individuals are better-off in period 2 if their productivity is low.

Lemma 1 If the government can observe the productivity of each individual, the unique time consistent optimal income tax equilibrium has $e_{i}^{* *}=0$ for all $i \in[0,1], T_{L}^{* *}=0$, and $m_{L}^{* *}=m_{L}^{*}$, with $m_{L}^{*}$ determined by (3). All individuals have low productivity and utility equal to $U^{* *}=u\left(m_{L}^{*}\right)-\psi_{L}\left(m_{L}^{*}\right)$. This utility level is strictly lower than the expected utility in the laissez-faire equilibrium.

The zero-investment result in Lemma 1 reproduces the time-consistent equilibrium outcome in Boadway et al. (1996). Most properties in Lemma 1 follow immediately from $e_{i}^{* *}=0$. In particular, $e_{i}^{* *}=0$ implies that all individuals have low productivity in period 2 and hence, are identical. No scope for welfare improving redistributive taxation emerges in period 1 . The utility level of each individual is strictly lower than the expected utility in the laissez-faire because $e_{i}=0$ was feasible in the laissez-faire case, and $e_{i}=0$ leads to precisely the same allocation in the laissez-faire and with optimal income taxation. It was shown in section 2, however, that a laissez-faire with strictly positive educational effort yields strictly a higher expected utility.

\section{Incomplete information}

Suppose now the government cannot observe each individual's true productivity. Educational investment choices are made in period 1. They are given in period 2. Also, the government correctly anticipates the share of individuals with high productivity. Let $\bar{p}$ be this share. The government cannot implement the massive redistribution program that equalizes marginal utilities of all individuals as in the case with a fully informed government in the previous section. Instead the welfarist government faces a standard optimal income tax problem. It must choose a pair of admissible combinations of gross earnings and taxes, $\left(m_{L}, T_{L}\right)$ and $\left(m_{H}, T_{H}\right)$, that maximize (6) subject to (7) and subject to the self-selection constraints

$$
u\left(m_{H}-T_{H}\right)-\psi_{H}\left(m_{H}\right) \geq u\left(m_{L}-T_{L}\right)-\psi_{H}\left(m_{L}\right)
$$

and

$$
u\left(m_{L}-T_{L}\right)-\psi_{L}\left(m_{L}\right) \geq u\left(m_{H}-T_{H}\right)-\psi_{L}\left(m_{H}\right)
$$


for the two productivity types. Constraint (9) requires that an individual with high productivity prefers to generate (high) income $m_{H}$ and pay (high) taxes $T_{H}$, compared to a choice of (low) income $m_{L}$ and a tax/subsidy equal to $T_{L}$, that is, an individual with high productivity prefers $\left(m_{H}, T_{H}\right)$ to $\left(m_{L}, T_{L}\right)$, and chooses $\left(m_{H}, T_{H}\right)$ if it has to make a choice between the two. Inequality (10) is an analogous constraint for individuals with low productivity, like in the two-type version as in Stern (1982) and Stiglitz (1982) of the standard Mirrlees (1971) framework. We discuss below how this program can be implemented by an income tax schedule with $T_{i}=T\left(m_{i}\right)$.

As is well known from similar problems, the self-selection constraint for the productive type, (9) will be binding, whereas (10) is not. The Lagrangian representing the maximization problem using $T_{L}=-\frac{\bar{p} T_{H}}{1-\bar{p}}$ is

$$
\mathcal{L}=W+\lambda\left[u\left(m_{H}-T_{H}\right)-\psi_{H}\left(m_{H}\right)-u\left(m_{L}+\frac{\bar{p} T_{H}}{1-\bar{p}}\right)+\psi_{H}\left(m_{L}\right)\right] .
$$

The first-order conditions are

$$
\begin{gathered}
\frac{\partial \mathcal{L}}{\partial m_{H}}=0 \Leftrightarrow(\bar{p}+\lambda)\left[u^{\prime}\left(x_{H}\right)-\psi_{H}^{\prime}\left(m_{H}\right)\right]=0 \\
\frac{\partial \mathcal{L}}{\partial m_{L}}=0 \Leftrightarrow(1-\bar{p})\left[u^{\prime}\left(x_{L}\right)-\psi_{L}^{\prime}\left(m_{L}\right)\right]-\lambda\left[u^{\prime}\left(x_{L}\right)-\psi_{H}^{\prime}\left(m_{L}\right)\right]=0 \\
\frac{\partial \mathcal{L}}{\partial T_{H}}=0 \Leftrightarrow-\bar{p} u^{\prime}\left(x_{H}\right)+\bar{p} u^{\prime}\left(x_{L}\right)+\lambda\left[-u^{\prime}\left(x_{H}\right)-\frac{\bar{p}}{1-\bar{p}} u^{\prime}\left(x_{L}\right)\right]=0 .
\end{gathered}
$$

Denote the optimal program as $\left(\hat{m}_{H}, \hat{T}_{H}\right),\left(\hat{m}_{L}, \hat{T}_{L}\right)$ and, accordingly, $\hat{x}_{H}=$ $\hat{m}_{H}-\hat{T}_{H}$, and $\hat{x}_{L}=\hat{m}_{L}-\hat{T}_{L}$. These optimal values are functions of the anticipated share $\bar{p}$ of high-productivity types which is affected by educational investment. Investment will be considered later.

Condition (12) is the no-distortion-at-the-top result. Conditions (13) and (14) characterize the standard solution of the welfarist government's problem of trading off the benefits of equalization of marginal utilities of consumption (that is, its redistributional goals) and the efficiency losses which result from making this redistribution compatible with the self-selection constraints. ${ }^{11}$

\footnotetext{
${ }^{11}$ In particular, (14) reveals that, in the optimal program, $u^{\prime}\left(\hat{x}_{L}\right)>u^{\prime}\left(\hat{x}_{H}\right)$. This inequality and (10) imply $\hat{m}_{L}<\hat{m}_{H}$. This, together with (12) shows that $\left[u^{\prime}\left(\hat{x}_{L}\right)-\right.$ $\left.\psi_{H}^{\prime}\left(\hat{m}_{L}\right)\right]>0$ in (13). Moreover, (13) can be fulfilled for positive $(1-p)$ and for positive $\lambda$ only if the two terms in brackets have the same sign. Hence, $u^{\prime}\left(\hat{x}_{L}\right)>\psi_{L}^{\prime}\left(\hat{m}_{L}\right)$. Unlike
} 
An important result is that the high-productivity type has a strictly higher period-2 utility than the low-productivity type in the optimal tax program. This distinguishes the equilibrium outcome with incomplete information from the complete information case. The result is due to the binding self-selection constraint (9) that is used to calculate the difference in period-2 utilities as

$$
\left[u\left(\hat{x}_{H}\right)-\psi_{H}\left(\hat{m}_{H}\right)\right]-\left[u\left(\hat{x}_{L}\right)-\psi_{L}\left(\hat{m}_{L}\right)\right] \underset{(9) \text { binding }}{=} \psi_{L}\left(\hat{m}_{L}\right)-\psi_{H}\left(\hat{m}_{L}\right)>0
$$

Note that the government can implement $\left(\hat{m}_{H}, \hat{T}_{H}\right)$ and $\left(\hat{m}_{L}, \hat{T}_{L}\right)$ by a standard type of tax policy in which the tax payment is a function of the observed gross income. For instance, for a tax function with

$$
T(m) \equiv\left\{\begin{array}{l}
\hat{T}_{L} \text { if } m \leq \hat{m}_{L} \\
\hat{T}_{H} \text { if } m>\hat{m}_{L}
\end{array}\right.
$$

the individuals with low-productivity strictly prefer $m=\hat{m}_{L}$ to any other amount of gross income, and individuals with high productivity are just indifferent between choosing gross income $\hat{m}_{L}$ or $\hat{m}_{H}$, and strictly prefer these amounts of gross income with the implied disutilities and taxes/subsidies to any other possible choice of gross income. Given their indifference between $\hat{m}_{L}$ or $\hat{m}_{H}$, as is standardly assumed in principal-agent theory, we adopt the tie-breaking rule that they choose $\hat{m}_{H}$.

Consider now STAGE 1: the investment in education. Individuals and the government anticipate that the share of individuals that have high productivity in period 2 is

$$
\bar{p}=\int_{0}^{1} p_{i}\left(e_{i}\right) d i
$$

This share is determined by all individuals' education choices made in period 1. In period 1 individuals will make their educational choices in the expectation that the government will implement the optimal program with $\left(\hat{m}_{H}, \hat{T}_{H}\right)$ and $\left(\hat{m}_{L}, \hat{T}_{L}\right)$, based on the anticipated aggregate share $\bar{p}$ of high-productivity types. Given that there are more than countably many individuals, they perceive correctly that their own choice determines their own probability $p\left(e_{i}\right)$

the full information case in (8), when information is incomplete the high-productivity type is left with higher net income than the low-productivity type. Net incomes are not fully equalized. Further, the earnings decision of the low-productivity type is distorted. Its earnings-generating effort is too low. 
of becoming a high-productivity type, but also understand that their own choice has no measurable impact on the aggregate $\bar{p}$, and, hence, on the optimal program to be chosen by the government in period $2 .{ }^{12}$

An individual's utility is higher by the amount determined in (15) if he or she has high-productivity. Hence, the individual's period-1 objective function becomes equivalent to

$$
p\left(e_{i}\right)\left[\psi_{L}\left(\hat{m}_{L}(\bar{p})\right)-\psi_{H}\left(\hat{m}_{L}(\bar{p})\right)\right]-e_{i}
$$

and the first-order condition becomes

$$
p^{\prime}\left(e_{i}\right)\left[\psi_{L}\left(\hat{m}_{L}(\bar{p})\right)-\psi_{H}\left(\hat{m}_{L}(\bar{p})\right)\right]=1 .
$$

The term in brackets is the period-2 utility difference between highly productive types and types with low productivity. It does not depend on $i$ 's educational choice, as $\partial \bar{p} / \partial e_{i}=0$ by (17). By the assumed concavity properties of $p\left(e_{i}\right)$ condition (19) has a unique solution for each possible $\bar{p}$, and the equilibrium educational investment $\hat{e}$ by all individuals is found where (19) is fulfilled for

$$
p\left(e_{i}\right)=\bar{p} .
$$

Inequality (15) together with $\lim _{e_{i} \rightarrow 0} p^{\prime}\left(e_{i}\right)=\infty$, imply that $\hat{e}>0$ in this equilibrium. Comparing $\hat{e}>0$ with the outcome with perfect information in section 4 reveals a central result of this analysis: Incomplete information reduces the underinvestment problem that occured in the time consistent optimal tax equilibrium with full information. However, investment $\hat{e}$ in the equilibrium with incomplete information is still smaller than in the laissezfaire equilibrium. (See the Appendix for a proof).

These properties are summarized as

Lemma 2 In the time consistent optimal tax equilibrium where type is not observable, all individuals choose the same amount of investment in education. This amount $\hat{e}$ is smaller than the laissez-faire amount, strictly

\footnotetext{
${ }^{12}$ Implicitly, this assumes that the government can also not observe the individual education effort. If the government could observe $e_{i}$, the government made use of this information to calculate $p\left(e_{i}\right)$, individual $i$ 's probability for becoming productive. The government then makes optimal individual contract offers $\left(m_{L}, T_{L}\right)_{i}$ and $\left(m_{H}, T_{H}\right)_{i}$ based on $p\left(e_{i}\right)$ instead of $\bar{p}$. Equilibrium education effort and ex-ante welfare are lower in this case, but still some investment in education occurs in the equilibrium, since highly productive individuals still earn an information rent.
} 
positive and larger than education with time consistent optimal taxation with complete information: $0=e^{* *}<\hat{e}<e^{*}$.

\section{Comparing welfare}

Three equilibria are compared: the laissez-faire equilibrium $\left(e^{*}, m_{H}^{*}, m_{L}^{*}\right)$ as in section 3, the time consistent optimal tax equilibrium where the government can observe individual productivity, with $e_{i}^{* *}=0, m_{L}^{* *}=m_{L}^{*}$ and $p^{* *}=p(0)=0$, as in section 5 , and the time consistent optimal tax equilibrium, where productivity types are unobservable, which was characterized by values $\left(\hat{e}, \hat{m}_{L}, \hat{m}_{H}, \hat{T}_{L}, \hat{T}_{H}\right)$ as described in section 6 .

It was already shown in section 5 that the laissez-faire equilibrium is Pareto superior to the time consistent optimal tax equilibrium with complete information.

The time consistent optimal tax equilibria with and without observability of individual productivity can also be ranked. The equilibrium in the situation that suffers from the additional information problem is superior to the equilibrium in the time consistent optimal tax equilibrium with full observability.

Theorem 1 Suppose the government chooses time consistent optimal income taxation in period 2. (i) The equilibrium with incomplete information has a higher expected utility (1) for each individual than the equilibrium with complete information. (ii) The equilibrium with incomplete information has a (weakly) higher period-2 utility for each individual than the equilibrium with complete information.

Proof. The expected utility of the time consistent optimal income tax equilibrium with complete information, as in section 5 , is identical to a period-2 equilibrium if all individuals had chosen education $e_{i}=0$ in the laissez faire. Expected utility in the laissez-faire is a monotonically increasing function in $e$ for $e \in\left[0, e^{*}\right)$. Further, for any given $\hat{e} \in(0,1)$, optimal redistributive income taxation with incomplete information increases the period-2 expected utility above the laissez-faire utility level that would be reached for this choice $\hat{e}$. Hence, the result (i) in Theorem 1 is implied by $e^{* *}=0<\hat{e}<e^{*}$, and this inequality was established in Lemma 2 .

Consider result (ii). Recall that the equilibrium with observability of types is characterized by $e_{i}^{* *}=0, p^{* *}=0, x_{i}^{* *}=m_{i}^{* *}=x_{L}^{*}=m_{L}^{*}$ for all 
individuals $i$. All individuals end up with low productivity and with the period-2 utility that low productivity individuals would have in the laissez faire. It has to be shown that period 2 utilities of the two types are

$$
u\left(\hat{x}_{L}\right)-\psi_{L}\left(\hat{m}_{L}\right) \geq u\left(m_{L}^{*}\right)-\psi_{L}\left(m_{L}^{*}\right)
$$

and

$$
u\left(\hat{x}_{H}\right)-\psi_{H}\left(\hat{m}_{H}\right) \geq u\left(m_{L}^{*}\right)-\psi_{L}\left(m_{L}^{*}\right) .
$$

If the optimal tax $\hat{T}_{H}=0,(20)$ is fulfilled because $\hat{x}_{L}=\hat{m}_{L}=x_{L}^{*}=m_{L}^{*}$ in this case, and (21) holds because $\hat{x}_{H}=\hat{m}_{H}>x_{L}^{*}=m_{L}^{*}$ and $u^{\prime}\left(\hat{x}_{H}\right)=$ $\psi_{H}^{\prime}\left(\hat{m}_{H}\right)$.

If, instead, $\hat{T}_{H}>0$, by $u^{\prime}\left(\hat{x}_{H}\right)=\psi_{H}^{\prime}\left(\hat{m}_{H}\right)$ this implies that the optimal tax reduces highly productive individuals' utility compared to $u\left(m_{H}^{*}\right)-\psi_{H}\left(m_{H}^{*}\right)$ for $\hat{T}_{H}>0$. Since the tax policy maximizes period-2 expected utility and there are only two types of productivity, the fact that highly productive individuals lose compared to the laissez-faire implies that individuals with low productivity must be better off than for $\hat{T}_{H}=0$. Therefore, (20) holds. (21) follows now from (20) because $u\left(\hat{x}_{H}\right)-\psi_{H}\left(\hat{m}_{H}\right) \underset{(9)}{\geq} u\left(\hat{x}_{L}\right)-\psi_{H}\left(\hat{m}_{L}\right)>$ $u\left(\hat{x}_{L}\right)-\psi_{L}\left(\hat{m}_{L}\right) \underset{(20)}{\geq} u\left(m_{L}^{*}\right)-\psi_{L}\left(m_{L}^{*}\right)$.

\section{Education policy}

Suppose the government can use some resources in period 1 to subsidize education investment. As individual education investment is assumed to be unobservable, the government cannot pay for actual education effort directly, but it can subsidize goods that are used when individuals invest in education. For instance, the government could provide free access to schools or universities, or subsidize education literature. Even if the government cannot observe if individuals actually learn or read the books, this reduces the individuals' cost of a given amount of education investment $e_{i}$. For simplicity I assume that a monetary subsidy of $\gamma e_{i}$ reduces the individual's cost of education effort $e_{i}$ to $(1-\gamma) e_{i}$. That is, I abstract from the possible deadweight loss that is incurred by the fact that actual education effort is unobservable and hence, can be subsidized only indirectly.

The timing in this section is as follows. At the beginning of period 1 the government decides on the subsidy rate $\gamma \in[0,1]$ that applies to education 
in that period. This completes STAGE 0 . The rest of the game proceeds as in sections 5 and 6: The individuals choose their education investments $e_{i}$, nature decides about each individual's productivity type, the government implements the time consistent optimal taxation in period 2 , and the individuals choose their earnings, pay their taxes, and the government redistributes the tax revenues.

If the government can observe individual productivity, education subsidies or even free education are completely ineffective:

Proposition 1 With complete information in period 2, for any education subsidy rate $\gamma \in[0,1]$ the equilibrium with time consistent optimal taxation has $e^{* *}=0$.

For a proof recall that, with complete information, highly productive individuals' period-2 utility is strictly lower than low-productivity types' period-2 utility in the time consistent optimal tax equilibrium. Hence, even if the government provides education for free, individuals have no incentive in period 1 to acquire education, because any education investment increases their probability to become highly productive, and hence, to end up with lower period-2 utility. Accordingly, complete information causes massive underinvestment, and the underinvestment problem cannot be alleviated, even if the government provides costless education. ${ }^{13}$ The result highlights that the mandatory element of education provision in Boadway et al. (1996) is essential for achieving a welfare improvement. Education would not be adopted by individuals voluntarily, even if it is freely provided.

Education subsidies can be more useful in the incomplete information case. The intuition of this result can be obtained from the marginal condition that determines individual education investment. If education effort is subsidized, the marginal condition determining individual education investment $e_{i}$ is

$$
(1-\gamma)=p^{\prime}\left(e_{i}\right)\left[\psi_{L}\left(m_{L}\right)-\psi_{H}\left(m_{L}\right)\right]
$$

Individuals invest because their investment increases the probability to become highly productive, and hence, their probability to earn the information rent $\left[\psi_{L}\left(m_{L}\right)-\psi_{H}\left(m_{L}\right)\right]$, where this information rent is determined by the

\footnotetext{
${ }^{13}$ The result relies on the fact that individuals are in a corner solution. The outcome is less extreme if, for instance, the first units of education yield sufficiently high private consumption benefits such that individuals choose some positive amount of education even in the full information case.
} 
time consistent optimal redistibutive taxation in period 2. If the information rent $\left[\psi_{L}\left(m_{L}\right)-\psi_{H}\left(m_{L}\right)\right]$ were independent of the equilibrium level of education and of the problem of financing the subsidy, the subsidy would unambigously increase equilibrium education, and, since we start in an equilibrium with underinvestment for $\gamma=0$, a small subsidy would increase welfare.

This result is reminiscent to results on subsidies on self-protection goods in moral hazard equilibria in private insurance markets that have been discussed, e.g., in Arnott and Stiglitz (1986, 1994). It is important to notice, however, that the case for subsidies is less clear here than in the standard moral hazard problem. An increase in the equilibrium investment $e$ also increases $p$, the equilibrium share of individuals with high productivity. This, in turn, will induce the government in period 2 to choose a pair of gross earnings and taxes $\left(m_{H}, T_{H}\right)$ and $\left(m_{L}, T_{L}\right)$ that provides a smaller information rent for the highly productive type, reducing their incentive to invest. Accordingly, the total effect of education subsidies in the incomplete information case depends on the shape of $p(e), \psi_{L}$ and $\psi_{H}$.

\section{Conclusions}

The standard view in welfare theory is that a strictly benevolent government's lack of information causes welfare losses. Examples are the efficiency cost of redistributive taxation, or the cost of preference revealing mechanisms. Privacy and the government's limited abilities to collect and process information are therefore seen as a cost.

This paper has shown that the government's limited ability to collect information can be beneficial, even if the government is strictly benevolent and maximizes the same objective function that all individuals unanimously agree to. The reason for this is a policy failure due to a time consistency problem in optimal income taxation. The welfare losses that are caused by this failure are reduced if the government is not fully informed about the earnings abilities of the citizens.

The results in this paper are consistent with a number of empirical observations and have strong policy implications. It is in line with the results in this paper that the constitutions in many countries limit the government's scope for information collection. Ex ante, such constraints are desirable, and can be interpreted as an attempt to commit future income tax policy. Also 
consistent with this theory, in many countries, an erosion of these constitutional limits can be observed. A most recent example is Germany's constitutional reform that allows to bug and secretly tape (almost) any private communication, if police suspects that these persons take part in organized crime activities. Similar to the time consistency problem with respect to the tax policy itself, any policy that limits the government's access to information is not time consistent. Once the educational investment has been made, full information and the radical redistribution it enables is preferable to incomplete information.

Technical progress and the implied improvement of information technology will increase the welfare losses that result from time consistent optimal income taxation. The time consistent optimal income tax is more strongly redistributive and, hence, educational effort is more strongly discouraged the better the government's access to information. Asymmetric information also improves governmental options for using public education as a second best policy.

\section{Appendix}

In this appendix we confirm $\hat{e}<e^{*}$. By strict concavity of $p\left(e_{i}\right)$, by (4), (15) and (19) it is sufficient to show that

$$
\begin{gathered}
{\left[\left[u\left(m_{H}^{*}\right)-\psi_{H}\left(m_{H}^{*}\right)\right]-\left[u\left(x_{L}^{*}\right)-\psi_{L}\left(m_{L}^{*}\right)\right]\right]>} \\
{\left[u\left(\hat{x}_{H}\right)-\psi_{H}\left(\hat{m}_{H}\right)\right]-\left[u\left(\hat{x}_{L}\right)-\psi_{L}\left(\hat{m}_{L}\right)\right] .}
\end{gathered}
$$

Conditions (2) and (12) together with $T_{H}>0$ imply that $\hat{m}_{H}>m_{H}^{*}=x_{H}^{*}>$ $\hat{x}_{H}$. This shows that

$$
\left[u\left(m_{H}^{*}\right)-\psi_{H}\left(m_{H}^{*}\right)\right]>\left[u\left(\hat{x}_{H}\right)-\psi_{H}\left(\hat{m}_{H}\right)\right] .
$$

It remains to show that $\left[u\left(x_{L}^{*}\right)-\psi_{L}\left(m_{L}^{*}\right)\right] \leq\left[u\left(\hat{x}_{L}\right)-\psi_{L}\left(\hat{m}_{L}\right)\right]$. This property follows from ex-post optimality of the optimal tax program. Note that the government can achieve period-2 utility of low-productivity types in period 2 equal to $u\left(x_{L}^{*}\right)-\psi_{L}\left(m_{L}^{*}\right)$ by a choice of zero taxes. If $\left[u\left(x_{L}^{*}\right)-\psi_{L}\left(m_{L}^{*}\right)\right]>$ $\left[u\left(\hat{x}_{L}\right)-\psi_{L}\left(\hat{m}_{L}\right)\right]$, then by $(24)$ both productivity types have lower period-2 utility with the period-2 optimal tax program than if the government decides in period 2 to choose zero taxes in that period. But by (24) the highproductivity type is also worse off in the optimal tax equilibrium than when 
government decides not to raise any taxes in period 2. Hence, in contradiction to the assumption, the optimal program $\left(\hat{m}_{H}, \hat{T}_{H}\right),\left(\hat{m}_{L}, \hat{T}_{L}\right)$ does not maximize period-2 welfare as defined in (6).

\section{References}

Arnott, R., and J.E. Stiglitz, 1986, Moral hazard and optimal commodity taxation, Journal of Public Economics, 29, 1-24.

Arnott, R., and J.E. Stiglitz, 1994, Information and economic efficiency, Information Economics and Policy, 6, 77-88.

Atkinson, A.B., 1973, How progressive sould income tax be?, in: M. Parkin and A.R. Nobay (eds.), Essays in Modern Economics, Longman, London, 90-109.

Boadway, R., and M. Keen, 1998, Evasion and time consistency in the taxation of capital income, forthcoming in: International Economic Review, 39, 461-476.

Boadway, R., N. Marceau and M. Marchand, 1996, Investment in education and the time inconsistency of redistributive tax policy, Economica, 63, 171-189.

Boadway, R. and M. Marchand, 1995, The use of public expenditures for redistributive purposes, Oxford Economic Papers, 47, 45-59.

Dillén, M. and M. Lundholm, 1996, Dynamic income taxation, redistribution, and the ratchet effect, Journal of Public Economics, 59, 69-93.

Edin, P.-A., and R. Topel, 1997, Wage policy and restructuring: the Swedish labor market since 1960, in: R.B. Freeman, R. Topel and B. Swedenborg (eds.), The welfare state in transition, reforming the Swedish model, the University of Chicago Press, Chicago, 155-201.

Kehoe, P.J., 1989, Policy cooperation among benevolent governments may be undesirable, Review of Economic Studies 56, 289-296.

Kjerstad, E., and S. Vagstad, 1996, Procurement auctions with entry of bidders, mimeo., University of Bergen.

Kotlikoff, L.J., T. Persson and L.E.O. Svensson, 1988, Social contracts as assets: a possible solution to the time consistency problem, American Economic Review, 78, 662-677.

Kydland, F., and E. Prescott, 1977, Rules rather than discretion: the inconsistency of optimal plans, Journal of Political Economy, 85, 473-490. 
Kydland, F. and E. Prescott, 1980, Dynamic optimal taxation, rational expectations and optimal control, Journal of Economic Dynamics and Control, 2, 79-91.

Mincer, J., 1994, Investment in U.S. education and training, NBER Working Paper no. 4844, Cambridge.

Mirrlees, J.A., 1971, An exploration in the theory of optimum income taxation, Review of Economic Studies, 38, 175-208.

Mirrlees, J.A., 1974, Notes on welfare economics, information and uncertainty, in: Balch and McFadden and Wu (eds.), Essays on economic behavior under uncertainty, North-Holland, Amsterdam, 243-258..

Persson, T., and G. Tabellini, 1994, Representative democracy and capital taxation, Journal of Public Economics, 55, 53-70.

Salant, D.J., 1991, A repeated game with finitely lived overlapping generations of players, Games and Economic Behavior, 3, 244-259.

Sinn, H.-W., 1995, A theory of the welfare state, Scandinavian Journal of Economics, 97(4), 495-526.

Stern, N.H., 1982, Optimum income taxation with errors in administration, Journal of Public Economics, 17, 181-211.

Stiglitz, J.E., 1982, Self-selection and Pareto efficient taxation, Journal of Public Economics, 17, 213-240.

Trostel, P.A., 1993, The effect of taxation on human capital, Journal of Political Economy, 101(2), 327-350.

Varian, H.R., 1980, Redistributive taxation as social insurance, Journal of Public Economics, 14, 49-68. 